\title{
Age-related participation and performance trends of children and adolescents in ultramarathon running
}

Scheer, Volker ; Di Gangi, Stefania ; Villiger, Elias ; Nikolaidis, Pantelis T ; Rosemann, Thomas ; Knechtle, Beat

\begin{abstract}
Participation and performance trends as well as the performance differences among sexes in ultraendurance running have been well described in the adult population; however, less information on such trends existed in youth ultramarathoners. The aim of the present study was to investigate the age-related participation and performance trends of children and adolescent ultramarathoner runners. Data on runners, younger than 19 years of age, competing from 1960 to 2018 in distance-limited ultramarathons of $50 \mathrm{~km}, 100 \mathrm{~km}, 50 \mathrm{miles}$ and 100 miles, were analysed. During this period, the number of ultramarathon participation increased, most notably among boys, most runners originated from Europe, and the 50- and 100-km race distances were the most popular. Overall, male runners were faster than female runners, except in the case of European and Oceanian origin, where girls were faster over the $50-\mathrm{km}$ race. The fastest male runners originated from Africa and the fastest girls from Oceania, and the average running speed has largely decreased for both sexes over calendar years. In summary, this study was the first to report details on participation and performance trends in youth ultramarathoners competing in distance-limited ultramarathons.
\end{abstract}

DOI: https://doi.org/10.1080/15438627.2020.1781124

Posted at the Zurich Open Repository and Archive, University of Zurich

ZORA URL: https://doi.org/10.5167/uzh-188235

Journal Article

Accepted Version

Originally published at:

Scheer, Volker; Di Gangi, Stefania; Villiger, Elias; Nikolaidis, Pantelis T; Rosemann, Thomas; Knechtle, Beat (2020). Age-related participation and performance trends of children and adolescents in ultramarathon running. Research in Sports Medicine, 28(4):507-517.

DOI: https://doi.org/10.1080/15438627.2020.1781124 
3

4

5

6

7

8

9

10

11

12

13

14

15

16

17

18

19

20

21

22

23

24

25

26

27

28

29

30

31

32

33

34

35

36

37

38

39

40

41

42

43

44

45

46

47

48

49

50

\section{Age-related participation and performance trends of children and adolescents in ultramarathon running}

\author{
Volker Scheer ${ }^{1,2}$, Stefania Di Gangi ${ }^{3}$, Elias Villiger ${ }^{3}$, \\ Pantelis T. Nikolaidis ${ }^{4}$, Thomas Rosemann ${ }^{3}$, Beat Knechtle ${ }^{3,5 *}$ \\ ${ }^{1}$ Ultra Sports Science Foundation, Pierre-Bénite, France \\ ${ }^{2}$ Health Science Department, Universidad a Distancia de Madrid (UDIMA), Madrid, Spain \\ ${ }^{3}$ Institute of Primary Care, University of Zurich \\ ${ }^{4}$ Exercise Physiology Laboratory, Nikaia, Greece \\ ${ }^{5}$ Medbase St. Gallen Am Vadianplatz, St. Gallen, Switzerland \\ Volker Scheer - volkerscheer@yahoo.com \\ Stefania Di Gangi - Stefania.DiGangi@usz.ch \\ Elias Villiger -evilliger@gmail.com \\ Pantelis Theodoros Nikolaidis - pademil@ hotmail.com \\ Thomas Rosemann - thomas.rosemann@usz.ch \\ Beat Knechtle - beat.knechtle@hispeed.ch
}

\section{* Correspondence:}

Prof. Dr. med. Beat Knechtle

Facharzt FMH für Allgemeinmedizin

Medbase St. Gallen Am Vadianplatz

Vadianstrasse 26

9001 St. Gallen

Switzerland

Telefon

Telefax

+41(0) 712269300

E-Mail

+41(0) 712269301

beat.knechtle@hispeed.ch 


\section{ABSTRACT}

52 Participation and performance trends as well as the performance differences among sexes in ultra-endurance running have been well described in the adult population; however, less information on such trends existed in youth ultramarathoners. The aim of the present study was to investigate the age-related participation and performance trends of children and adolescent ultramarathoner runners. Data on runners, younger than 19 years of age, competing from 1960 to 2018 in distance-limited ultramarathons of $50 \mathrm{~km}, 100 \mathrm{~km}, 50$ miles and 100 miles, were analysed. During this period, the number of ultramarathon participation increased, most notably among boys, most runners originated from Europe, and the 50- and 100-km race distances were the most popular. Overall, male runners were faster than female runners, except in the case of European and Oceanian origin, where girls were faster over the

$62 \quad 50-\mathrm{km}$ race. The fastest male runners originated from Africa and the fastest girls from

63 Oceania, and the average running speed has largely decreased for both sexes over calendar

64 years. In summary, this study was the first to report details on participation and performance trends in youth ultramarathoners competing in distance-limited ultramarathons.

66 Key words: boy, girl, ultra-endurance, running, ultramarathon 


\section{INTRODUCTION}

77 The participation in ultra-endurance activities has increased over the last few decades (Costa,

78 Knechtle, Tarnopolsky, \& Hoffman, 2019; Scheer, 2019). This trend included ultra-endurance

79 running events with distances over the traditional marathon distance of $42.195 \mathrm{~km}$ (Scheer \&

80 Murray, 2015). Participation and performance trends (da Fonseca-Engelhardt et al., 2013;

81 Knechtle, Rüst, Rosemann, \& Lepers, 2012) as well as the performance differences among

82 sexes (in half-marathon, marathon and ultra-marathon) were well described in the adult

83 population (Eichenberger, Knechtle, Rust, Rosemann, \& Lepers, 2012; Knechtle \&

84 Nikolaidis, 2018a; Nikolaidis, Cuk, Clemente-Suárez, Villiger, \& Knechtle, 2020).

85 Performance trends of master athletes in ultramarathons have also been studied (Zingg, Rüst,

86 Lepers, Rosemann, \& Knechtle, 2013).

87 Data on childhood participation in ultra-endurance events are limited, but one study described

88 an exponential increase in participation over the last 20 years (Scheer \& Hoffman, 2019). The

89 age group with the greatest number of finishers was the 16-18-year olds, but even children as

90 young as 10 years old finished ultra-endurance events (Scheer \& Hoffman, 2019). The most

91 popular running distances included the $50 \mathrm{~km}$ and $100 \mathrm{~km}$ events with the majority of finishers

92 being boys (Scheer \& Hoffman, 2019).

93 Performance and performance trends in this young ultra-endurance population would be of

94 interest, especially as it could aid fitness trainers and coaches working with young athletes to

95 set optimal training goals. Therefore, the aim of the current study was to fill this gap by

96 investigating performance times and trends at different ultra-endurance distances, age groups

97 and countries of origin. 


\section{MATERIALS AND METHODS}

\section{Ethics approval}

102 The study was approved by medical council (Ärztekammer Westfalen Lippe, Germany) and

103 the University of Münster, Germany (Chairperson Prof. Berdel, protocol number 2018-304-f-

$104 \mathrm{~S}$ ), and all procedures adhered to the principles derived from the Declaration of Helsinki.

105 Data sampling and data analysis

106 All data were accessed in the website of DUV (Deutsche Ultramarathon Vereinigung), where

107 all race results of ultramarathons were recorded (https://statistik.d-u-v.org/index.php).

108 A computer script was written to retrieve a list for every event recorded on the website. Each

109 event's web page was then read by the script to extract the complete data table available. The

110 script compiled all that data into one large excel file which was our starting point for further

111 manual filtering of relevant information.

112 We analysed data of distance-limited races (50 km, 50 miles, $100 \mathrm{~km}$ and 100 miles) from

1131960 to 2018. The following variables were analysed: year of race, race distance, name of the

114 race, race time or performance (h:min:s), name of athlete, year of birth, nationality and sex of

115 athlete. Running speed $(\mathrm{km} / \mathrm{h})$ was calculated from the time and distance variables. Age was

116 derived by subtracting the year of birth from the year when the race was held. Continent

117 variable was defined from the nationality of the athletes. Inclusion criterion was that

118 participants finished either a 50-km, 50-miles, 100-km or 100-mile race between 1960 and

119 2018, and were under the age of 19. Data from participants that were implausible (e.g., age

120 under 13 years) were excluded from further analyses.

121 


\section{Statistical analysis}

123 Running speed $(\mathrm{km} / \mathrm{h})$ was the main outcome measure. Information of all races concerning

124 number of observations, mean (SD) and minimum and maximum of speed $(\mathrm{km} / \mathrm{h})$ was

125 provided (Table 1). Distance-limited races of 100 miles were excluded from the main

126 analyses due to insufficient data ( $<100$ observations). Descriptive statistics were presented as

127 means and SD (standard deviations) by sex, age groups, continents and time groups. The age

128 groups were $10-13,14-15,16-17$ and 18 years. Continent groups, with reference to the

129 nationality of the athletes, were: Africa, Asia, Central-South America, Europe, North-

130 America, Oceania. When the number of observations of each continent group, within each

131 race, was not greater than 10 , continents were grouped together into other continents. To

132 show performance by period of time, calendar year of the race was grouped into time-periods

133 of 10 years. Age and calendar year were considered as continuous variables in 1-year

134 intervals, when defined as predictor variables for ultramarathon speed. In fact, non-linear

135 regression mixed models, with basis splines (BS), were performed to examine the time trend

136 together with the effects of sex, age and continent on the speed time of each distance race.

137 The mixed models were used to correct for repeated measurements within runners (clusters)

138 through the random effects of intercepts. The statistical models were specified as follows:

139 Ultramarathon running speed $(\mathrm{Y}) \sim[$ Fixed effects $(\mathrm{X})=\mathrm{BS}($ Year, $\mathrm{df}=3)+\mathrm{BS}($ Age, $\mathrm{df}=3)+$

140 continent + sex $*$ continent + [random effects of intercept=runners]

141 where BS(Year, $\mathrm{df}=3$ ) and BS(Age, $\mathrm{df}=3$ ) were 3 degrees of freedom ( $\mathrm{df}$ ) basis splines

142 changing with calendar year and age, respectively; sex*continent denote the sex-continent

143 interaction term. Different analyses were performed, one for each distance $(50 \mathrm{~km}, 50$ miles,

$144100 \mathrm{~km})$. The interaction term sex-continent was significant and considered only in the $50 \mathrm{~km}$

145 analysis. In the $100 \mathrm{~km}$ analysis, since the fit was better, a linear term on age, instead of the 
146 relative spline term, was considered. Results of the regression models were presented as

147 estimates and standard errors. Statistical significance was defined as $p<0.05$. All statistical

148 analyses were carried out with R, R Core Team (2016). R: A language and environment for

149 statistical computing. R Foundation for Statistical Computing, Vienna, Austria. URL

150 https://www.R-project.org/.The R packages ggplot2, lme4, and lmerTest were used,

151 respectively, for data visualization and for the mixed models.

152

153

154

155

156

157

158

159 


\section{RESULTS}

161 A total of 2,083 records on 1,496 different finishers with information on age were retrieved

162 from the database on 50-km ultramarathon races between 1977 and 2018. For $100 \mathrm{~km}$ race, a

163 total of 2,057 records on 1815 different finishers was available for the period between 1960

164 and 2018. In 50-/100-km races, the number of women was $289(19.3 \%) / 112$ (6.2\%) with 399

165 (19.2\% of the total observations) / 132 (6.4\% of the total observations) records, and the

166 number of men was 1,207 (80.7\%) / 1,703 (93.8\%) with 1,684 (80.8\%)/1925 (93.6\%) records.

167 In $50 \mathrm{~km}$ and 50 miles, the majority of finishers were $16-17$ years old $(\mathrm{n}=823,39.5 \%$; $\mathrm{n}=404$,

$16842.2 \%$, respectively), followed by 18 years old $(n=795,38.2 \% ; n=359,37.5 \%)$. In $100 \mathrm{~km}$, the

169 vast majority of finishers were 18 years old, $n=1,458$ (70.9\%). In $50 \mathrm{~km}$ and 50 miles, the vast

170 majority of finishers came from North-America, $n=1,739(83.5 \%)$ and $n=856(89.4 \%)$

171 respectively.

172 Most finishers that participated in $100 \mathrm{~km}$ races came from Europe 1,903 (92.5\%). In distance

173 races, the highest number of participations occurred during the years between 2010-2018,

174 especially in $50 \mathrm{~km}$ with 1,534 (73.6\%) and in 50 miles $451(47.1 \%)$. Instead, in $100 \mathrm{~km}$,

$17580.5 \%$ of observations were recorded before 1990.The number of observations and the

176 average performance by sex, age groups and continent were reported in Table 2. Moreover,

177 the number of observations and the average performance by time groups was reported in

178 Table 3. In Figure 1, participation (\%) and average performances $(\mathrm{km} / \mathrm{h})$ for $50 \mathrm{~km} / \mathrm{h}$

179 distance race were shown by nationality. Accordingly, figures for the other distance races

180 were reported as supplemental material (Figures S1-S2). The results of the statistical models,

181 as described in the methods section, were reported as supplemental material (Table S1). Boys

182 were significantly faster than girls in all races. The largest sex differences were observed in

183 the $50 \mathrm{~km}$ and 50 miles races, where boys were on average $0.76 \mathrm{~km} / \mathrm{h}(\mathrm{SE}=0.12, p<0.001)$ and 
$1840.78 \mathrm{~km} / \mathrm{h}(\mathrm{SE}=0.15, p<0.001)$ faster than girls, respectively. Compared to North-America,

185 European children and adolescents were significantly faster in $50 \mathrm{~km}$ races $(1.69 \mathrm{~km} / \mathrm{h}$

$186(\mathrm{SE}=0.42, p<0.001))$ but slower in 50 miles races $(0.70 \mathrm{~km} / \mathrm{h}(\mathrm{SE}=0.30, p<0.05))$ and faster in

$187100 \mathrm{~km}$ races $(1.50 \mathrm{~km} / \mathrm{h}(\mathrm{SE}=0.21, p<0.001))$. Compared to North-America, runners from

188 other continents (i.e. Africa, Central-South America and Oceania) were on average faster in

$189100 \mathrm{~km}$ races $(1.94 \mathrm{~km} / \mathrm{h}(\mathrm{SE}=0.53))$. In $50 \mathrm{~km}$ races, the $\mathrm{Sex} *$ Continent interaction showed

190 that boys from Africa were significantly faster (on average $3.77 \mathrm{~km} / \mathrm{h}(\mathrm{SE}=1.82)$ ), depicting

191 the largest distance between the fitted curves in boys and girls for African finishers, although

192 numbers were small. All the effects presented in Table $\mathbf{S 1}$ were shown graphically for 50

$193 \mathrm{~km} / \mathrm{h}$ distance race in Figures 2 and Figure S3 and for the other distance races in Figures S4-

194 S7.

195 Running speed increased across age groups in $50 \mathrm{~km}$ (Figure 2) and 50 miles (Figure S4). In

$196100 \mathrm{~km}$, age had no significant effect (Figure S6). Across calendar years, running speed

197 decreased in both girls and boys for all nationalities in $50 \mathrm{~km}$ (Figure S3). In 50-miles

198 (Figure S5) and 100-km races (Figure S7), running speed increased and then decreased

199 across calendar years.

200

201

202

203

204

205 


\section{DISCUSSION}

207 The aim of the present study was to investigate the age-related participation and performance

208 trends of children and adolescent ultramarathoner runners. The main findings were $(i)$ the

209 number of ultramarathon participation increases over time, most notably among boys (ii) 50

210 and $100 \mathrm{~km}$ race distances were the most popular, with most runners originating from Europe

211 (iii) boys were generally faster than girls, with the fastest male runners originating from

212 Africa, and fastest girls from Oceania (iv) European girls and girls from Oceania were faster

213 over the $50 \mathrm{~km}$ distance compared to boys from the same continent, and $(v)$ the average

214 running speed over calendar years largely decreased for both sexes.

\section{Participation trends by distance}

216 An exponential increase in participation numbers among male ultramarathoners was observed

217 since the 2000s, whereas there was a more gradual, linear increase starting mostly over the

218 last decade in females. The most popular running distances were those of $50 \mathrm{~km}$ and $100 \mathrm{~km}$,

219 followed by 50 miles and 100 miles races, although participation in the latter two were

220 significantly less. There was no female participation in the $50 \mathrm{~km}$ until the $1980 \mathrm{~s}$. This

221 observation confirmed previous findings in young ultramarathon runners (Scheer \& Hoffman,

222 2018). Similar participation trends might be observed in the adult population, with the 50km

223 distance being the most popular running distance (Scheer, 2019). The increased participation

224 of young athletes in ultra-marathon events might be attributed to the overall increased

225 participation in ultra-marathon races observed in adult runners (Knechtle \& Nikolaidis,

226 2018a).

227 The majority of finishers belonged to the older age groups (16-18 years of age) and were

228 mostly male. In 18-year old boys, the $100 \mathrm{~km}$ distance was the most popular, followed by 50

$229 \mathrm{~km}$ and 50 miles. In girls, the $50 \mathrm{~km}$ distance was the most popular distance, and among boys 
ranging from 10-17 years of age. The findings in line with previously published data (Scheer

231 \& Hoffman, 2018).

\section{$232 \quad$ Participation trends by continent}

233 Most ultramarathon runners originated from Europe, with the $100 \mathrm{~km}$ distance being the most

234 popular one. Similar findings in adult ultramarathon runners confirmed this trend, as most 100

$235 \mathrm{~km}$ race finishers came from Europe (Cejka et al., 2014; Knechtle, Nikolaidis, \& Valeri,

236 2018). Runners from North America were the second largest group, with a preference for the

$23750 \mathrm{~km}$ distance, for both boys and girls alike. Participation numbers from other continents

238 were low, although the $50 \mathrm{~km}$ distance was the most popular among them. The $100 \mathrm{~km}$ were

239 mostly run by European boys and girls. The 50 miles were almost exclusively run by athletes

240 from North America. This may hardly be surprising as 50-mile races were rarely held in

241 Europe. This was also shown in master ultramarathoners, where most 50-mile runners

242 originated from the USA (Waldvogel, Nikolaidis, Di Gangi, Rosemann, \& Knechtle, 2019).

243 Performance analysis: Running speed by distance, age and calendar year

244 Running speed increased across age groups in $50 \mathrm{~km}$ and 50 miles races. In $100 \mathrm{~km}$ races,

245 however, age had no significant effect. In other terms, boys and girls improved their running

246 performance with increasing age with the exception of the $100 \mathrm{~km}$ ultramarathon distance.

247 However, they are still far away from the age of peak ultramarathon performance which is

248 generally achieved at ages older than 35 years (Cejka et al., 2014; Knechtle, Di Gangi, Rüst,

249 Rosemann, \& Nikolaidis, 2018; Nikolaidis \& Knechtle, 2018). It is well-known that the age

250 of peak performance in endurance sports increases with increasing length or duration of the

251 endurance performance (Allen \& Hopkins, 2015). 
252 Boys were generally faster than girls, apart from European girls and girls from Oceania over

253 the $50 \mathrm{~km}$ distance compared to boys from the same continent. This is an interesting finding

254 as for adult ultramarathoners, men are generally faster than women in $50 \mathrm{~km}$ and $100 \mathrm{~km}$

255 races (Zingg et al., 2014). One possible explanation may be that there were only a small

256 number of girls participating in the $50 \mathrm{~km}$ event, compared to larger number of participating

257 boys and that girls may have been better trained and prepared for this particular event. In the

258 50-mile events boys were faster than girls, with a peak in average speed in the 1980s and a

259 gradual decline thereafter. Male adult runners are faster than women across all mile races with

260 distances ranging from 50 miles to 3100 miles (Zingg, Knechtle, Rosemann, \& Rust, 2015).

261 In adults, women, however, have closed the gap to men in the last decades (Peter, Rüst,

262 Knechtle, Rosemann, \& Lepers, 2014; Waldvogel et al., 2019; Zingg et al., 2014; Zingg et al.,

263 2015), something that could not be observed among our group of young ultramarathon

264 runners.

265 In $50 \mathrm{~km}$ races, running speed decreased in both girls and boys for all nationalities. In 50

266 miles and $100 \mathrm{~km}$ races, running speed increased and then decreased across calendar years.

267 Taken together, these youth ultramarathoners were not able to improve their running

268 performance in the last years although in some races (e.g., 50 miles and $100 \mathrm{~km}$ races) in

269 earlier years their running speed was higher than in the last years. This decrease in speed may

270 be due to the overall increasing participation, especially from less trained athletes, a

271 phenomenon, that has been observed in adult ultramarathoners in $50 \mathrm{~km}$ (Nikolaidis \&

272 Knechtle, 2018) and $100 \mathrm{~km}$ races (Knechtle, Di Gangi, et al., 2018). In addition, marathon

273 races times have also become slower in the last years (Knechtle, Di Gangi, Rust, \&

274 Nikolaidis, 2019; Knechtle \& Nikolaidis, 2018a; Nikolaidis, Rosemann, \& Knechtle, 2018),

275 possibly for the same reason.

276 


\section{Performance analysis: Running speed by continent and distance}

278 The fastest male runners in the $50 \mathrm{~km}$ distance originated from Africa, followed by Europe

279 and Oceania but participation numbers compared to European runners were very low. In girls

280 the fastest runners came from Oceania followed by Europe and North America. As mentioned

281 before, European and Oceanian girls were faster than their male counterparts. The 100km

282 were mostly run by European boys and girls, however the fastest average speed was observed

283 in Asian boys and girls. The 50 miles were mostly run by runners from North America. Elite

284 adult ultramarathoners runners mostly originated from Japan (Nikolaidis, Onywera, \&

285 Knechtle, 2017), but no such classification system or record books existed in youth runners.

286 The increase of participation of youth ultra-runners raised questions about long-term health

287 implications of these events and whether children should participate in these events at all

288 (Scheer \& Hoffman, 2018). Data from childhood participation in marathons suggested that

289 there were no acute adverse health outcomes (Roberts, 2007); however, data on ultra-distance

290 running in the youth athlete were currently not available and no consensus about guaranteed

291 safe running distances exist (Roberts, 2007). The musculoskeletal system was of particular

292 interest since it was immature during childhood and especially vulnerable for injuries at

293 growth plates, tendon attachments, and/or articular cartilage at joint surfaces (Krabak, Snitily,

294 \& Milani, 2016). Other aspects to consider during maturation were brain development with

295 enhancement of cognitive and psychological function, especially since ultra-endurance

296 running could be an intense stressor on cognitive performance (Hurdiel et al., 2018), induce

297 changes within the autonomic nervous system (Vieluf, Scheer, Hasija, Schreier, \&

298 Reinsberger, 2019) and impair rational decision-making processes in adults (Hoffman \&

299 Krouse, 2018).Examining the long-term health implications of childhood ultra-running would

300 be an important area of future research and until such date would be available it might be 
301 prudent to consider individual medical, physiological, biomechanical and psychological

302 developments when recommending youth athletes to participate in ultra-running events.

\section{$303 \quad$ Limitations}

304 The DUV database was the largest ultra-running database worldwide, which has been widely

305 used to gain insights into participation and performance trends (Knechtle et al., 2019;

306 Knechtle \& Nikolaidis, 2018b; Scheer \& Hoffman, 2018); however, not all results may be

307 completely accurate with any large dataset. The subset of DUV data was previously analysed

308 and any questionable data cross checked with the ultrasignup.com database, another popular

309 ultra-running result database, trying to eliminate any inaccuracies (Scheer \& Hoffman, 2018).

310 Races with the same distance were grouped together for calculation of average speed. This

311 was a limitation, as specific race characteristics with respect to running surface, elevation

312 change, environmental conditions and level of support were not taken into consideration

313 (Scheer et al., 2020). However, due to the retrospective character of the study, the multitude

314 of different races across calendar years, calculation and comparisons of individual speeds for

315 each race and calendar year was not feasible.

\section{Conclusion}

317 In summary, participation in childhood and adolescent ultramarathon running was on the rise,

318 with the majority of runners originating from Europe and North America. The $50 \mathrm{~km}$ and 100

$319 \mathrm{~km}$ distances were the most popular and boys were overall faster than girls, with the fastest

320 boys originating from Africa and Asia, and the fastest girls coming from Oceania and Asia,

321 over the $50 \mathrm{~km}$ and $100 \mathrm{~km}$, respectively. 


\section{REFERENCES}

324

325

326

327

328

329

330

331

332

333

334

335

336

337

338

339

340

341

342

343

344

345

346

347

348

349

350

351

352

353

354

355

356

357

358

359

360

361

362

363

Allen, S. V., \& Hopkins, W. G. (2015). Age of Peak Competitive Performance of Elite Athletes: A Systematic Review. Sports Medicine, 45(10), 1431-1441. doi: 10.1007/s40279-015-0354-3

Cejka, N., Rüst, C. A., Lepers, R., Onywera, V., Rosemann, T., \& Knechtle, B. (2014). Participation and performance trends in 100-km ultra-marathons worldwide. Journal of Sports Sciences, 32(4), 354-366. doi: 10.1080/02640414.2013.825729

Costa, R. J. S., Knechtle, B., Tarnopolsky, M., \& Hoffman, M. D. (2019). Nutrition for ultramarathon running: Trail, track, and road. International Journal of Sport Nutrition and Exercise Metabolism, 29(2), 130-140. doi: 10.1123/ijsnem.2018-0255

da Fonseca-Engelhardt, K., Knechtle, B., Rüst, C. A., Knechtle, P., Lepers, R., \& Rosemann, T. (2013). Participation and performance trends in ultra-endurance running races under extreme conditions - 'Spartathlon' versus 'Badwater'. Extreme Physiology and Medicine, 2(1). doi: 10.1186/2046-7648-2-15

Eichenberger, E., Knechtle, B., Rust, C. A., Rosemann, T., \& Lepers, R. (2012). Age and sex interactions in mountain ultramarathon running - the Swiss Alpine Marathon. Open Access J Sports Med, 3, 73-80. doi: 10.2147/oajsm.s33836

Hoffman, M. D., \& Krouse, R. (2018). Ultra-obligatory running among ultramarathon runners. Res Sports Med, 26(2), 211-221. doi: 10.1080/15438627.2018.1431533

Hurdiel, R., Riedy, S. M., Millet, G. P., Mauvieux, B., Peze, T., Elsworth-Edelsten, C., . . Dupont, G. (2018). Cognitive performance and self-reported sleepiness are modulated by time-of-day during a mountain ultramarathon. Res Sports Med, 26(4), 482-489. doi: $10.1080 / 15438627.2018 .1492401$

Knechtle, B., Di Gangi, S., Rüst, C. A., Rosemann, T., \& Nikolaidis, P. T. (2018). Men's Participation and Performance in the Boston Marathon from 1897 to 2017. International Journal of Sports Medicine, 39(13), 1018-1027. doi: 10.1055/a-06600061

Knechtle, B., Di Gangi, S., Rust, C. A., \& Nikolaidis, P. T. (2019). Performance Differences Between the Sexes in the Boston Marathon From 1972 to 2017. J Strength Cond Res. doi: $10.1519 /$ jsc.0000000000002760

Knechtle, B., \& Nikolaidis, P. T. (2018a). Physiology and pathophysiology in ultra-marathon running. Frontiers in Physiology, 9(JUN). doi: 10.3389/fphys.2018.00634

Knechtle, B., \& Nikolaidis, P. T. (2018b). Sex- and age-related differences in half-marathon performance and competitiveness in the world's largest half-marathon - the GoteborgsVarvet. Res Sports Med, 26(1), 75-85. doi: $10.1080 / 15438627.2017 .1393749$

Knechtle, B., Nikolaidis, P. T., \& Valeri, F. (2018). Russians are the fastest 100-km ultramarathoners in the world. PLoS ONE, 13(7). doi: 10.1371/journal.pone.0199701

Knechtle, B., Rüst, C. A., Rosemann, T., \& Lepers, R. (2012). Age-related changes in 100-km ultra-marathon running performance. Age, 34(4), 1033-1045. doi: 10.1007/s11357011-9290-9 
402

403

404

405

406

Krabak, B. J., Snitily, B., \& Milani, C. J. (2016). Running Injuries During Adolescence and Childhood. Phys Med Rehabil Clin N Am, 27(1), 179-202. doi: 10.1016/j.pmr.2015.08.010

Nikolaidis, P. T., \& Knechtle, B. (2018). Age of peak performance in 50-km ultramarathoners - is it older than in marathoners? Open Access J Sports Med, 9, 37-45. doi: 10.2147/oajsm.s154816

Nikolaidis, P. T., Onywera, V. O., \& Knechtle, B. (2017). Running performance, nationality, sex, and age in the $10-\mathrm{km}$, half-marathon marathon, and the $100-\mathrm{km}$ ultramarathon IAAF 1999-2015. J Strength Cond Res, 31(8), 2189-2207.

Nikolaidis, P. T., Rosemann, T., \& Knechtle, B. (2018). Sex differences in the age of peak marathon race time. Chinese Journal of Physiology, 61(2), 85-91. doi: 10.4077/CJP.2018.BAG535

Nikolaidis, P.T., Cuk, I., Clemente-Suárez, V.J., Villiger, E., \& Knechtle, B. (2020). Number of finishers and performance of age group women and men in long-distance running: comparison among 10km, half-marathon and marathon races in Oslo. Res Sports Med, 11:1-11. doi: 10.1080/15438627.2020.1726745. [Epub ahead of print]

Peter, L., Rüst, C. A., Knechtle, B., Rosemann, T., \& Lepers, R. (2014). Sex differences in 24-hour ultra-marathon performance - A retrospective data analysis from 1977 to 2012. Clinics, 69(1), 38-46. doi: 10.6061/clinics/2014(01)06

Roberts, W. O. (2007). Can children and adolescents run marathons? Sports Med, 37(4-5), 299-301. doi: 10.2165/00007256-200737040-00007

Scheer, B. V., \& Murray, D. A. (2015). Ultramarathon Running Injuries. In M. N. Doral \& J. Karlsson (Eds.), Sports Injuries. Berlin: Springer.

Scheer, V. (2019). Participation trends of ultra endurance events. Sports Medicine and Arthroscopy Review, 27(1), 3-7. doi: 10.1097/JSA.0000000000000198

Scheer, V., Basset, P., Giovanelli, N., Vernillo, G., Millet, G. P., \& Costa, R. J. S. (2020). Defining Off-road Running: A Position Statement from the Ultra Sports Science Foundation. Int J Sports Med(EFirst). doi: 10.1055/a-1096-0980

Scheer, V., \& Hoffman, M. D. (2018). Should children be running ultramarathons? Current Sports Medicine Reports, 17(9), 282-283. doi: 10.1249/JSR.0000000000000512

Scheer, V., \& Hoffman, M. D. (2019). Too much too early? An analysis of worldwide childhood ultramarathon participation and attrition in adulthood. J Sports Med Phys Fitness, 59(8), 1363-1368. doi: 10.23736/s0022-4707.19.09495-7

Vieluf, S., Scheer, V., Hasija, T., Schreier, P. J., \& Reinsberger, C. (2019). Multimodal approach towards understanding the changes in the autonomic nervous system induced by an ultramarathon. Res Sports Med, 1-10. doi: 10.1080/15438627.2019.1665522

Waldvogel, K. J., Nikolaidis, P. T., Di Gangi, S., Rosemann, T., \& Knechtle, B. (2019). Women reduce the performance difference to men with increasing age in ultramarathon running. International Journal of Environmental Research and Public Health, 16(13). doi: 10.3390/ijerph16132377

Zingg, M., Rüst, C. A., Lepers, R., Rosemann, T., \& Knechtle, B. (2013). Master runners dominate 24-h ultramarathons worldwide-a retrospective data analysis from 1998 to 2011. Extreme Physiology and Medicine, 2(1). doi: 10.1186/2046-7648-2-21 
407

408

409

410

411

412
Zingg, M. A., Karner-Rezek, K., Rosemann, T., Knechtle, B., Lepers, R., \& Rüst, C. A. (2014). Will women outrun men in ultra-marathon road races from $50 \mathrm{~km}$ to 1,000 km? SpringerPlus, 3(1). doi: 10.1186/2193-1801-3-97

Zingg, M. A., Knechtle, B., Rosemann, T., \& Rust, C. A. (2015). Performance differences between sexes in 50-mile to 3,100-mile ultramarathons. Open Access J Sports Med, 6, 7-21. doi: 10.2147/oajsm.s76490 
413 Table 1- Ultramarathon performance - speed $\mathrm{km} / \mathrm{h}$ by distance. Mean (SD) and minimum 414 (Min), maximum (Max) were reported.

415

\begin{tabular}{lllll}
\hline Distance & \multicolumn{5}{c}{ Speed (km/h) } \\
\hline & N & Mean (SD) & Min & Max \\
\hline Distance & & & & \\
\hline $50 \mathrm{~km}$ & 2083 & $7.78(1.88)$ & 1.75 & 15.46 \\
$50 \mathrm{mi}$ & 958 & $7.39(1.50)$ & 1.73 & 14.08 \\
$100 \mathrm{~km}$ & 2057 & $5.95(1.52)$ & 3.18 & 14.52 \\
$10 \mathrm{mi}$ & 81 & $5.79(1.26)$ & 2.65 & 9.96 \\
\hline
\end{tabular}

416

417

418

419

420

421

422

423

424

425

426

427

428

429

430 
431 Table 2. Mean and (SD) of ultramarathon performance speed in $\mathrm{km} / \mathrm{h}$. Distance races: $50 \mathrm{~km}$, $43250 \mathrm{mi}$ and $100 \mathrm{~km}$ by sex, age and country (continent). Africa, Central-South America and 433 Oceania, due to small sample size for $100 \mathrm{~km}$ races, were grouped together into "Other" 434 group; for 50 mi the group "Other" included also Asia.

\begin{tabular}{|c|c|c|c|c|c|c|c|}
\hline \multicolumn{2}{|c|}{ Distance } & \multicolumn{2}{|c|}{$50 \mathrm{~km}, \mathrm{~N}=2083$} & \multicolumn{2}{|c|}{$50 \mathrm{mi}, \mathrm{N}=958$} & \multicolumn{2}{|c|}{100 km, N=2057 } \\
\hline Age & Sex & $\mathbf{N}$ & Mean (SD) & $\mathbf{N}$ & Mean (SD) & $\mathbf{N}$ & Mean (SD) \\
\hline \multirow[t]{2}{*}{$10-13$} & $\mathrm{~F}$ & 21 & $6.16(1.45)$ & 6 & $5.91(2.31)$ & 2 & $5.09(0.98)$ \\
\hline & M & 143 & $7.25(1.81)$ & 54 & $6.80(2.04)$ & 25 & $7.05(2.49)$ \\
\hline \multirow[t]{2}{*}{$14-15$} & $\mathrm{~F}$ & 56 & $7.06(1.88)$ & 15 & $6.39(1.01)$ & 5 & $5.51(0.48)$ \\
\hline & M & 245 & 7.63 (1.66) & 120 & 7.05 (1.46) & 95 & $6.66(1.72)$ \\
\hline \multirow[t]{2}{*}{$16-17$} & $\mathrm{~F}$ & 148 & $7.21(1.58)$ & 40 & $6.58(1.00)$ & 37 & $5.92(1.44)$ \\
\hline & M & 675 & 7.98 (1.90) & 364 & $7.44(1.36)$ & 435 & $6.09(1.36)$ \\
\hline \multirow[t]{2}{*}{18} & $\mathrm{~F}$ & 174 & 7.38 (1.67) & 47 & $6.82(1.10)$ & 88 & $5.86(2.11)$ \\
\hline & M & 621 & 8.11 (1.97) & 312 & $7.82(1.49)$ & 1370 & $5.84(1.47)$ \\
\hline Continent & Sex & $\mathbf{N}$ & Mean (SD) & $\mathbf{N}$ & Mean (SD) & $\mathbf{N}$ & Mean (SD) \\
\hline \multirow{2}{*}{$\begin{array}{l}\text { North- } \\
\text { America }\end{array}$} & $\mathrm{F}$ & 348 & $7.16(1.60)$ & 101 & $6.63(1.17)$ & 10 & $6.04(1.18)$ \\
\hline & M & 1391 & $7.92(1.74)$ & 755 & $7.52(1.54)$ & 59 & $7.41(2.01)$ \\
\hline \multirow[t]{2}{*}{ Africa } & $\mathrm{F}$ & 1 & 4.50 & - & - & - & - \\
\hline & M & 13 & $9.22(3.75)$ & - & - & - & - \\
\hline \multirow[t]{2}{*}{ Asia } & $\mathrm{F}$ & 16 & $6.18(1.00)$ & - & - & 7 & $6.23(2.08)$ \\
\hline & M & 86 & $6.64(2.18)$ & - & - & 66 & $7.61(1.53)$ \\
\hline $\begin{array}{l}\text { Central- } \\
\text { South }\end{array}$ & $\mathrm{F}$ & 8 & $6.06(1.04)$ & - & - & - & - \\
\hline America & M & 33 & 6.89 (1.65) & & - & - & - \\
\hline Europe & $\mathrm{F}$ & 19 & $8.86(2.08)$ & 1 & 5.44 & 110 & $5.70(1.88)$ \\
\hline
\end{tabular}




\begin{tabular}{|c|c|c|c|c|c|c|c|}
\hline & $\mathrm{M}$ & 143 & $8.72(2.52)$ & 20 & $6.83(1.67)$ & 1793 & $5.83(1.37)$ \\
\hline \multirow[t]{2}{*}{ Oceania } & $\mathrm{F}$ & 7 & $9.11(1.78)$ & - & - & - & - \\
\hline & M & 18 & $8.44(1.56)$ & - & - & - & - \\
\hline \multirow[t]{2}{*}{ Other } & $\mathrm{F}$ & - & - & 6 & $6.57(0.77)$ & 5 & $8.16(1.44)$ \\
\hline & $\mathrm{M}$ & - & - & 75 & $7.33(1.07)$ & 7 & $10.54(3.44)$ \\
\hline
\end{tabular}

435

436

437

438

439

440

441

442

443

444

445

446

447

448

449

450

451

452

453

454

455 
Table 3. Mean and (SD) of ultramarathon performance speed in km/h. Distance races: $50 \mathrm{~km}$, $45750 \mathrm{mi}$ and $100 \mathrm{~km}$ by calendar year groups.

\begin{tabular}{|c|c|c|c|c|c|c|c|}
\hline \multicolumn{2}{|l|}{ Distance } & \multicolumn{2}{|c|}{$50 \mathrm{~km}, \mathrm{~N}=2083$} & \multicolumn{2}{|c|}{$50 \mathrm{mi}, \mathrm{N}=958$} & \multicolumn{2}{|c|}{$100 \mathrm{~km}, \mathrm{~N}=2057$} \\
\hline Year & Sex & $\mathbf{N}$ & Mean (SD) & $\mathbf{N}$ & Mean (SD) & $\mathbf{N}$ & Mean (SD) \\
\hline \multirow[t]{2}{*}{1960 - 1969} & $\mathrm{~F}$ & - & - & 1 & 7.53 & 13 & $4.71(0.59)$ \\
\hline & $\mathrm{M}$ & - & - & 12 & $6.39(0.70)$ & 259 & $5.13(0.73)$ \\
\hline \multirow[t]{2}{*}{1970 - 1979} & $\mathrm{~F}$ & - & - & 4 & $6.98(1.21)$ & 45 & $5.29(0.85)$ \\
\hline & M & 5 & $9.55(1.62)$ & 123 & $7.36(1.41)$ & 853 & $5.76(1.10)$ \\
\hline \multirow[t]{2}{*}{$1980-1989$} & $\mathrm{~F}$ & 6 & $11.05(1.74)$ & 3 & $6.61(0.79)$ & 22 & $5.52(0.91)$ \\
\hline & $\mathrm{M}$ & 44 & $9.90(1.70)$ & 102 & $8.15(1.50)$ & 464 & $6.29(1.53)$ \\
\hline \multirow[t]{2}{*}{$1990-1999$} & $\mathrm{~F}$ & 21 & $8.04(1.78)$ & 15 & $6.95(0.86)$ & 13 & $9.21(2.95)$ \\
\hline & M & 70 & $9.17(2.26)$ & 76 & $7.56(1.39)$ & 83 & $7.06(2.33)$ \\
\hline \multirow[t]{2}{*}{$2000-2009$} & $\mathrm{~F}$ & 60 & $7.28(1.35)$ & 16 & $7.04(0.98)$ & 15 & $5.40(2.02)$ \\
\hline & $\mathrm{M}$ & 343 & $8.25(1.70)$ & 155 & $7.64(1.55)$ & 98 & $6.50(2.01)$ \\
\hline \multirow[t]{2}{*}{$2010-2018$} & $\mathrm{~F}$ & 312 & $7.06(1.62)$ & 69 & $6.42(1.23)$ & 24 & $6.27(1.64)$ \\
\hline & M & 1222 & $7.67(1.86)$ & 382 & $7.31(1.50)$ & 168 & $6.41(2.15)$ \\
\hline
\end{tabular}

458

459

460

461

462

463

464

465 
$466 \quad$ Figure legends

467

468 Figure 1 Participation $(\%)$ and average performance $(\mathrm{km} / \mathrm{h})$ by nationality in $50-\mathrm{km}$

469 races.

470 Figure 2 Running speed by age groups and continent in 50-km races. Fitted values=line Points=mean of observed values.

472

473

474

475

476

477

478

479

480

481

482

483

484 


\section{Country participation in $\mathbf{5 0 ~ k m ~}$}

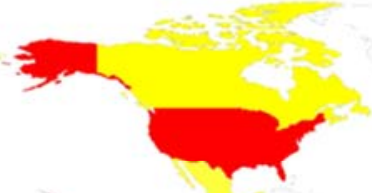

Frequency (\%)

$<=1 \%=2 \%-3 \%=5-10 \%-25 \%-50 \%-50 \%$

Country performance in $\mathbf{5 0 ~ k m}$

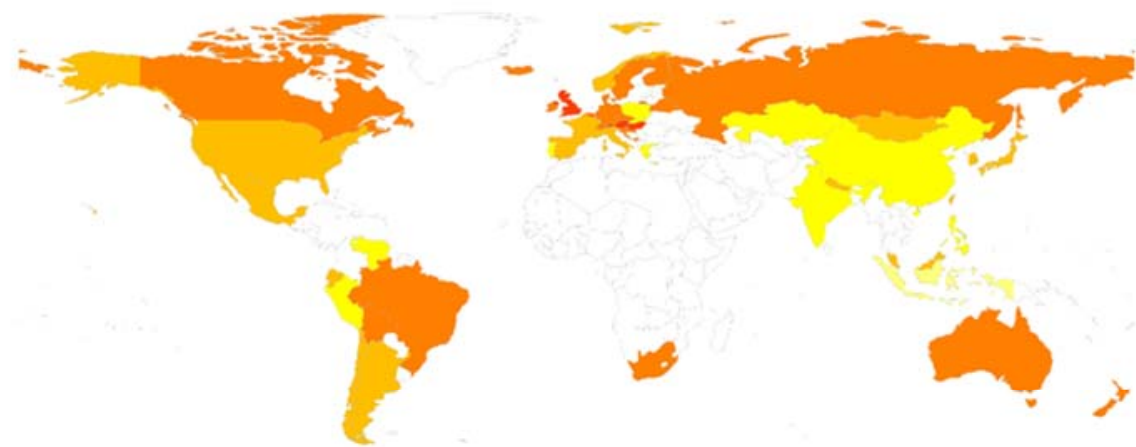

Speed $(\mathrm{km} / \mathrm{h})$

$2-4 \square 4-6 \square 6-8 \square 8-10=10-12=12-14$

485

486 Figure 1 


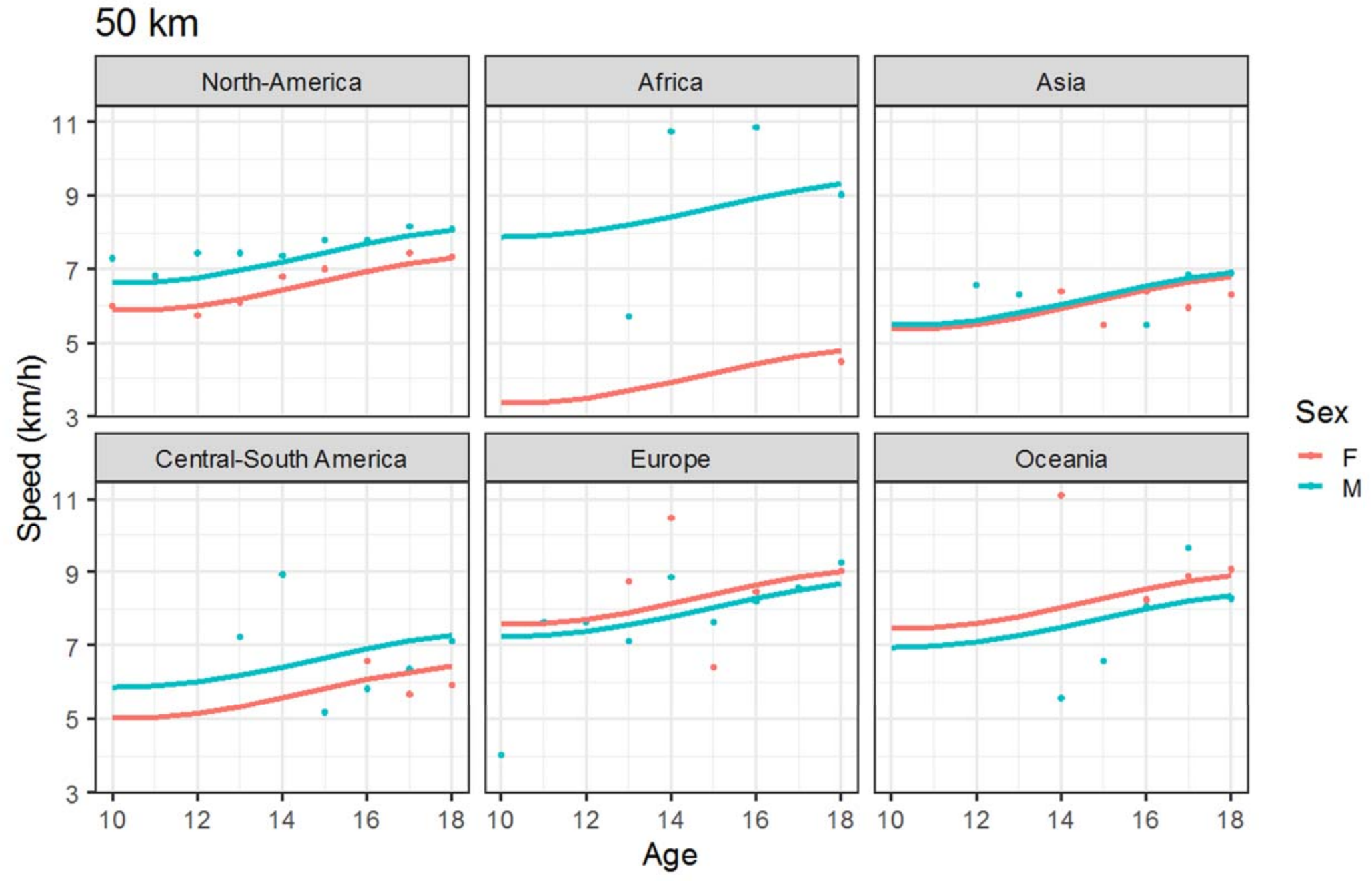

487

488 Figure 2 
490 Table S1. Regression analysis (mixed model) of ultramarathon (50 km, 50 miles and 100 $491 \mathrm{~km}$ ). Estimates and standard errors (SE) of fixed effects are reported. P-values ranges are 492 marked with asterisks (see note). Smoothing terms, basis splines (BS), are denoted with BS(x) $493 \mathrm{t}$, where $\mathrm{x}=$ year, age; $\mathrm{t}=1,2,3$. In $50 \mathrm{~km}$, we considered observations from 1980 onward.

\begin{tabular}{|c|c|c|c|}
\hline & \multicolumn{3}{|c|}{ Distance-limited races } \\
\hline & $50 \mathrm{~km}$ & 50 miles & $100 \mathrm{~km}$ \\
\hline \multicolumn{4}{|l|}{ Age effect } \\
\hline BS $($ Age $) 1$ & $-0.130(0.616)$ & $0.293(0.925)$ & \\
\hline BS $($ Age $) 2$ & $1.092^{* *}(0.336)$ & $0.839(0.477)$ & \\
\hline BS (Age) 3 & $1.414^{* * *}(0.325)$ & $1.717^{* * *}(0.512)$ & \\
\hline Age & & & $0.033(0.025)$ \\
\hline \multicolumn{4}{|l|}{ Year effect } \\
\hline BS(Year) 1 & $-1.341(0.867)$ & $3.319^{* * *}(0.955)$ & $1.043^{*}(0.523)$ \\
\hline BS(Year)2 & $-2.255 * * *(0.427)$ & $0.911 *(0.372)$ & $3.796 * * *(0.329$ \\
\hline BS(Year)3 & $-2.829 * * *(0.418)$ & $0.843(0.461)$ & $0.116(0.317)$ \\
\hline \multicolumn{4}{|l|}{$\begin{array}{l}\text { Continent effect(ref. } \\
\text { North-America) }\end{array}$} \\
\hline Asia & $-0.513(0.535)$ & & $0.246(0.254)$ \\
\hline Africa & $-2.527(1.750)$ & & \\
\hline Central-South America & $-0.872(0.659)$ & & \\
\hline Europe & $1.695 * * *(0.424)$ & $-0.705 *(0.302)$ & $1.497 * * *(0.211)$ \\
\hline Oceania & $1.586(0.839)$ & & \\
\hline Other & & $0.286(0.171)$ & $1.944 * * *(0.528)$ \\
\hline Sex effect & & & \\
\hline
\end{tabular}




\begin{tabular}{|c|c|c|c|}
\hline $\operatorname{Sex}=M(\operatorname{ref}=F)$ & $0.762 * * *(0.121)$ & $0.776 * * *(0.152)$ & $0.455^{* * * *(0.132)}$ \\
\hline \multicolumn{4}{|l|}{$\begin{array}{l}\text { Interaction effect } \\
\text { Sex: Continent }\end{array}$} \\
\hline M: Africa & $3.767^{*}(1.823)$ & & \\
\hline M: Asia & $-0.644(0.575)$ & & \\
\hline M: Central-South America & $0.087(0.730)$ & & \\
\hline M: Europe & $-1.100 *(0.454)$ & & \\
\hline M: Oceania & $-1.285(0.958)$ & & \\
\hline Constant & $8.394^{* * *}(0.510)$ & $4.127^{* * *}(0.665)$ & $5.166^{* * *}(0.531)$ \\
\hline Observations & 2078 & 958 & 2057 \\
\hline Runners & 1491 & 765 & 1815 \\
\hline Note: & ${ }^{*} \mathrm{p}<0.05^{* *} \mathrm{p}<0.01^{* * *}$ & $p<0.001$ & \\
\hline
\end{tabular}

494

495

496

497

498

499

500

501

502

503

504

505

506 
507 Figure S1 Participation (\%)and average performance $(\mathrm{km} / \mathrm{h})$ by nationality in 50 miles races.

509 Figure S2 Participation (\%)and average performance $(\mathrm{km} / \mathrm{h})$ by nationality in $100-\mathrm{km}$ races.

511 Figure S3 Running speed across years and continent in 50-km races. Fitted values=line.

512 Points $=$ mean of observed values .

513 Figure S4 Running speed by age groups and continent in 50-miles races. Fitted

514 values=line. Points=mean of observed values.

515 Figure S5 Running speed across years and continent in 50-miles races. Fitted values=line.

$516 \quad$ Points=mean of observed values.

517 Figure S6 Running speed by age groups and continent in 100-km races. Fitted

518 values=line. Points=mean of observed values.

519 Figure S7 Running speed across years and continent in 100-km races. Fitted values=line. $520 \quad$ Points=mean of observed values.

521

522

523

524

525

526

527

528

529 
Country participation in $\mathbf{5 0}$ miles

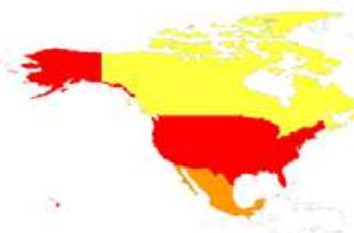

Frequency $(\%)$

\begin{tabular}{|c|c|c|c|c|}
\hline \multicolumn{5}{|c|}{ Frequency (\%) } \\
\hline$<=1 \%$ & $2 \%$ & $3-4 \%$ & $5-10 \%$ & $=10-25 \%=25-50 \%=50-90 \%$ \\
\hline
\end{tabular}

Country performance in $\mathbf{5 0}$ miles

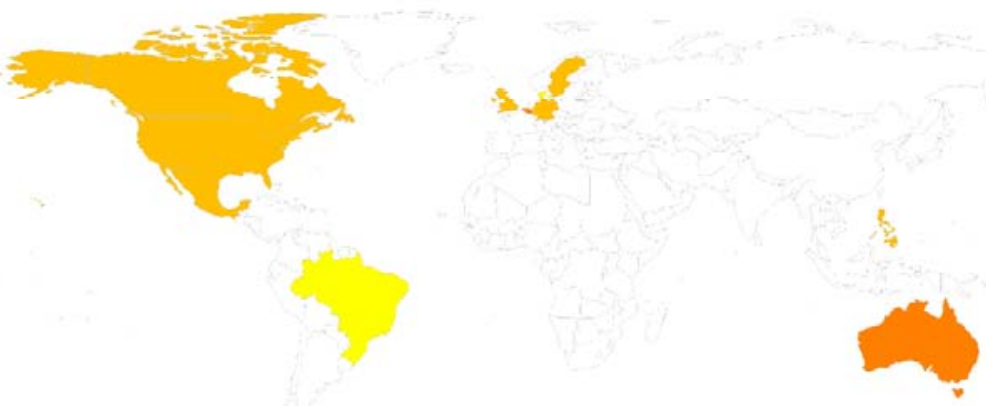

Speed $(\mathrm{km} / \mathrm{h})$
$\square 2-4 \square$ 4-6 $\square-8 \quad \square-10 \square 10-12 \square 12-14$

555

556 Figure S1 


\section{Country participation in 100 km}

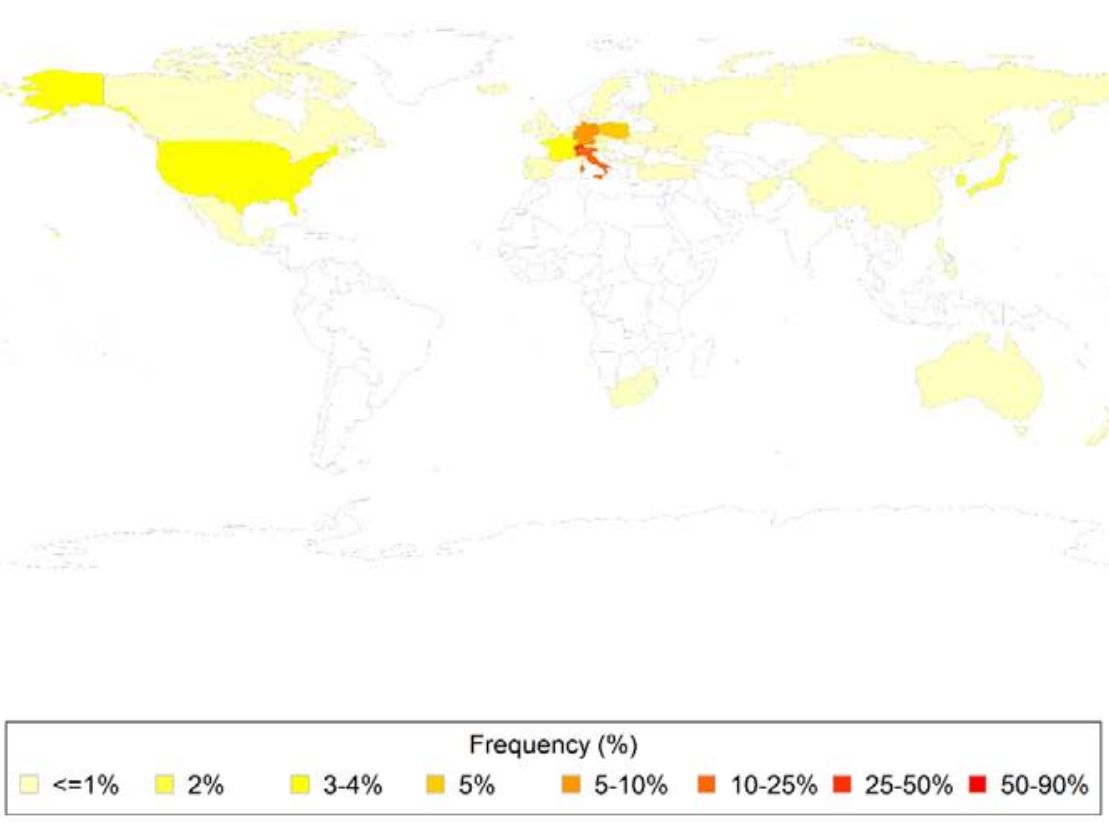

Country performance in $100 \mathrm{~km}$
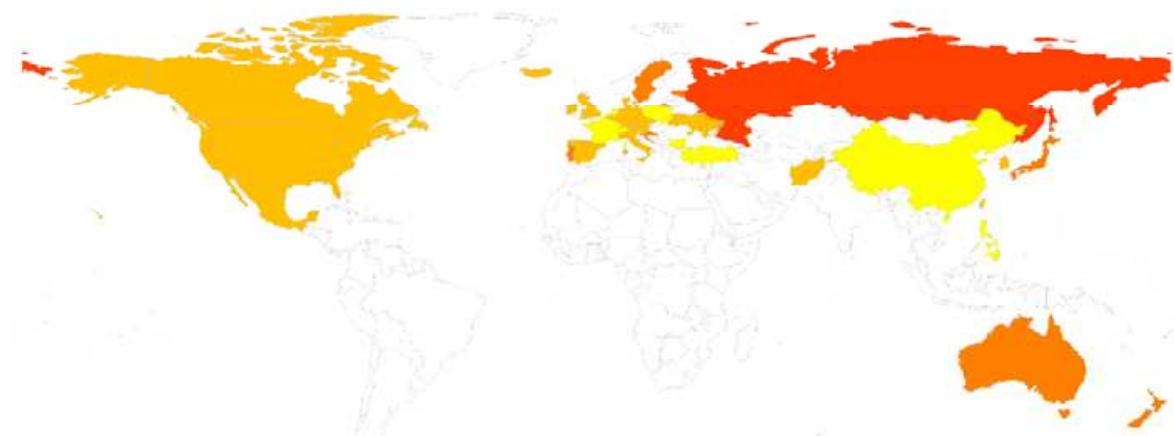

\begin{tabular}{|c|c|c|c|c|}
\hline \multicolumn{5}{|c|}{ Speed $(\mathrm{km} / \mathrm{h})$} \\
\hline $2-4$ & $4-6$ & $6-8$ & $8-10$ & $10-12 \square 12-14$ \\
\hline
\end{tabular}

557

558 Figure S2 
$50 \mathrm{~km}$
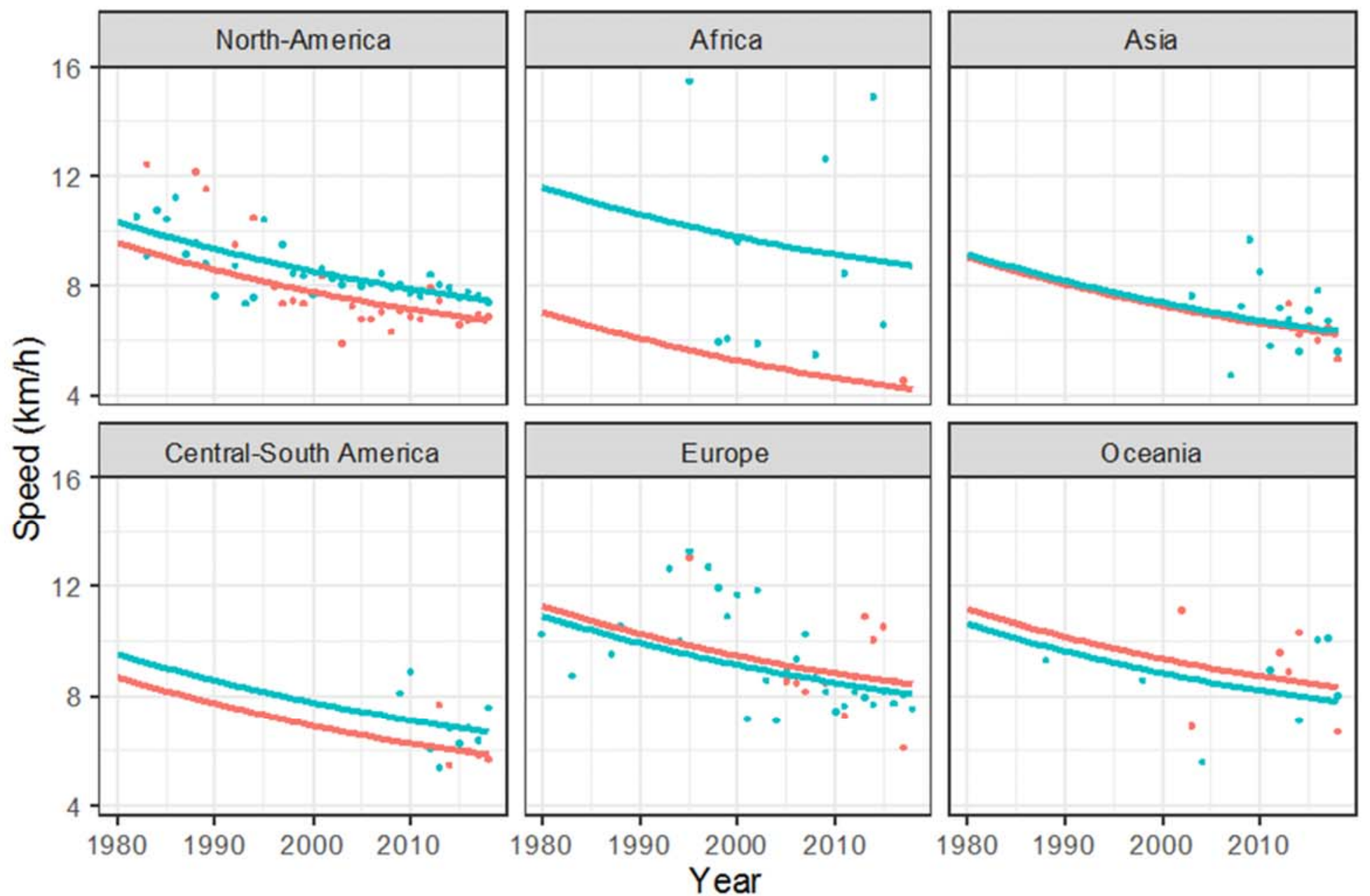

Sex

559

Figure S3 


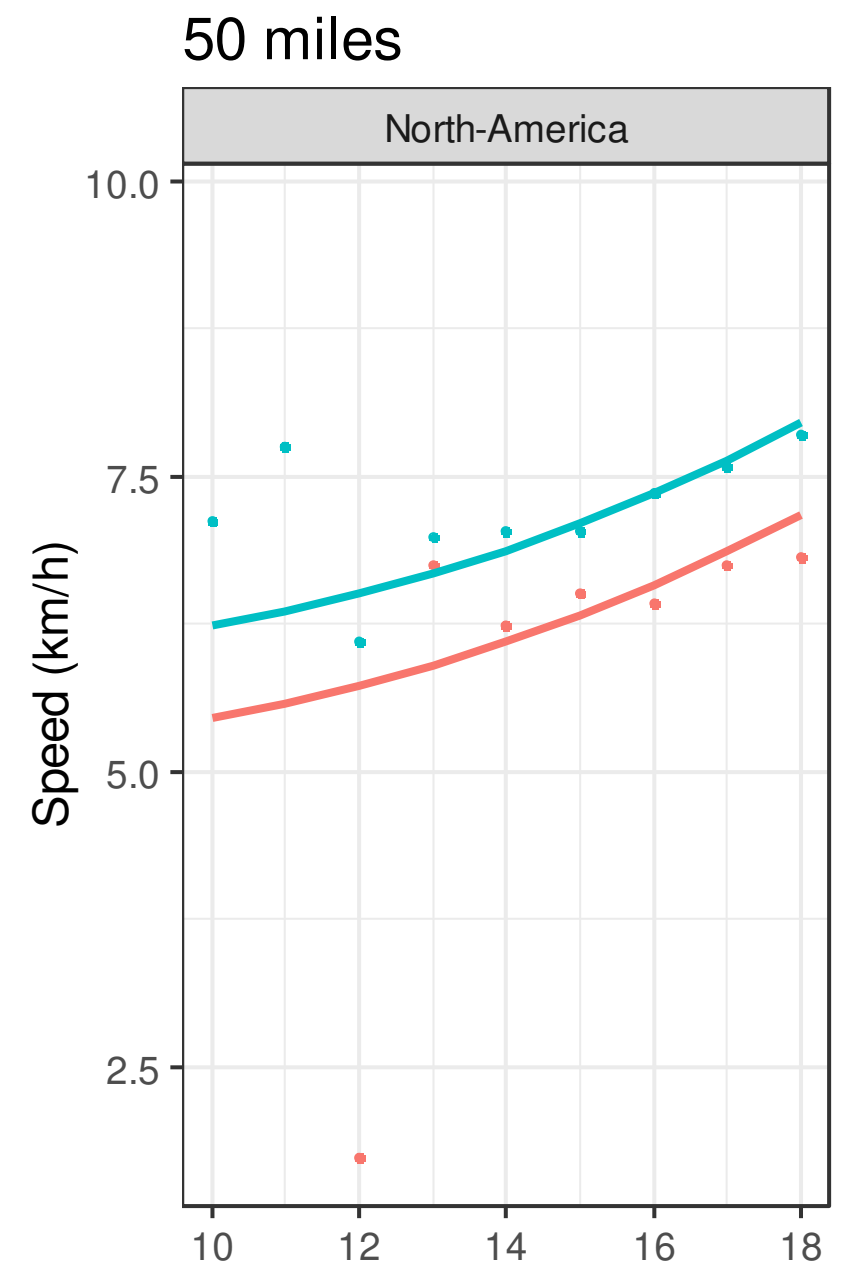

561
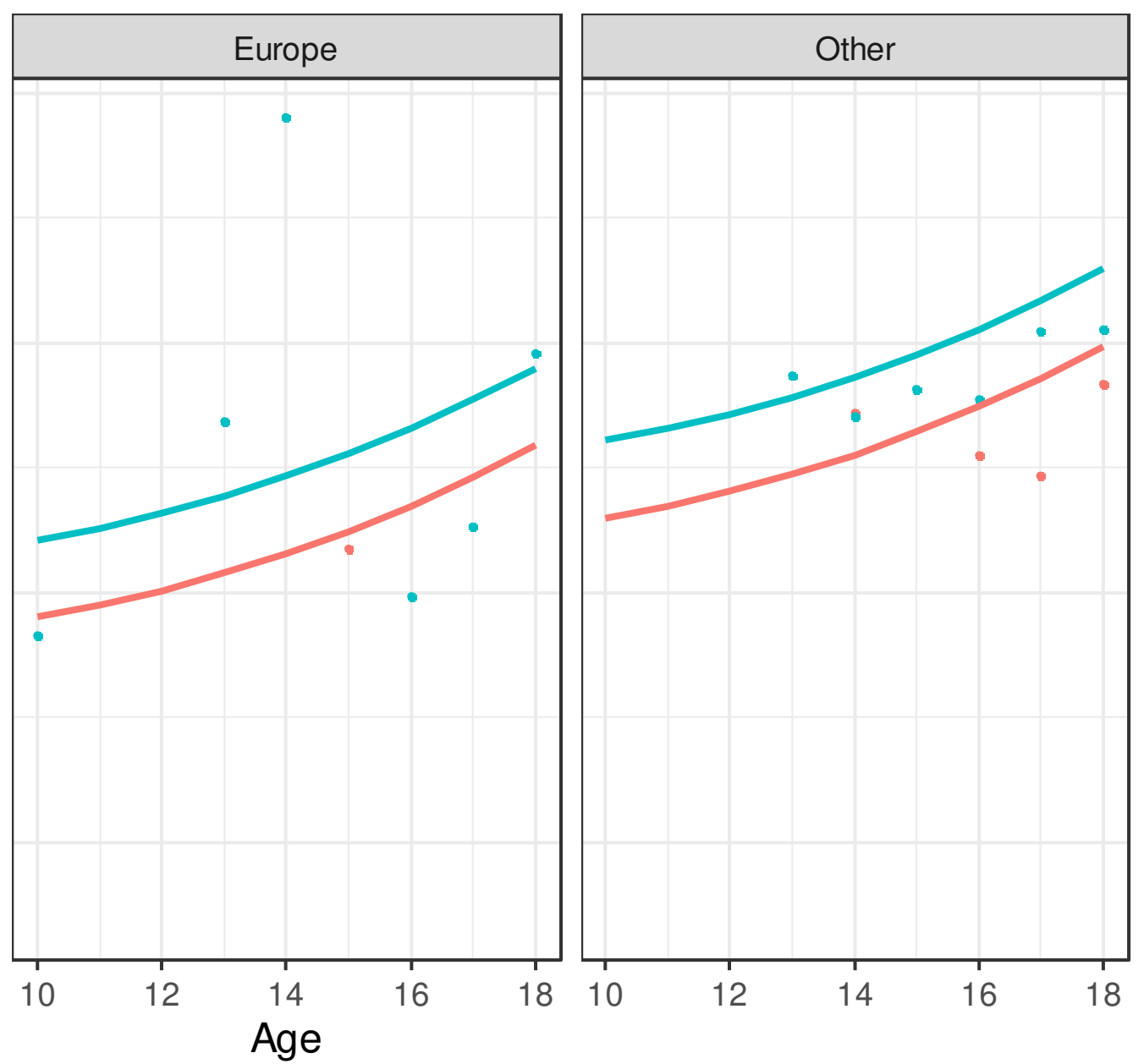

Sex

$-F$
$-\quad M$

$562 \quad$ Figure S4 


\section{0 miles}
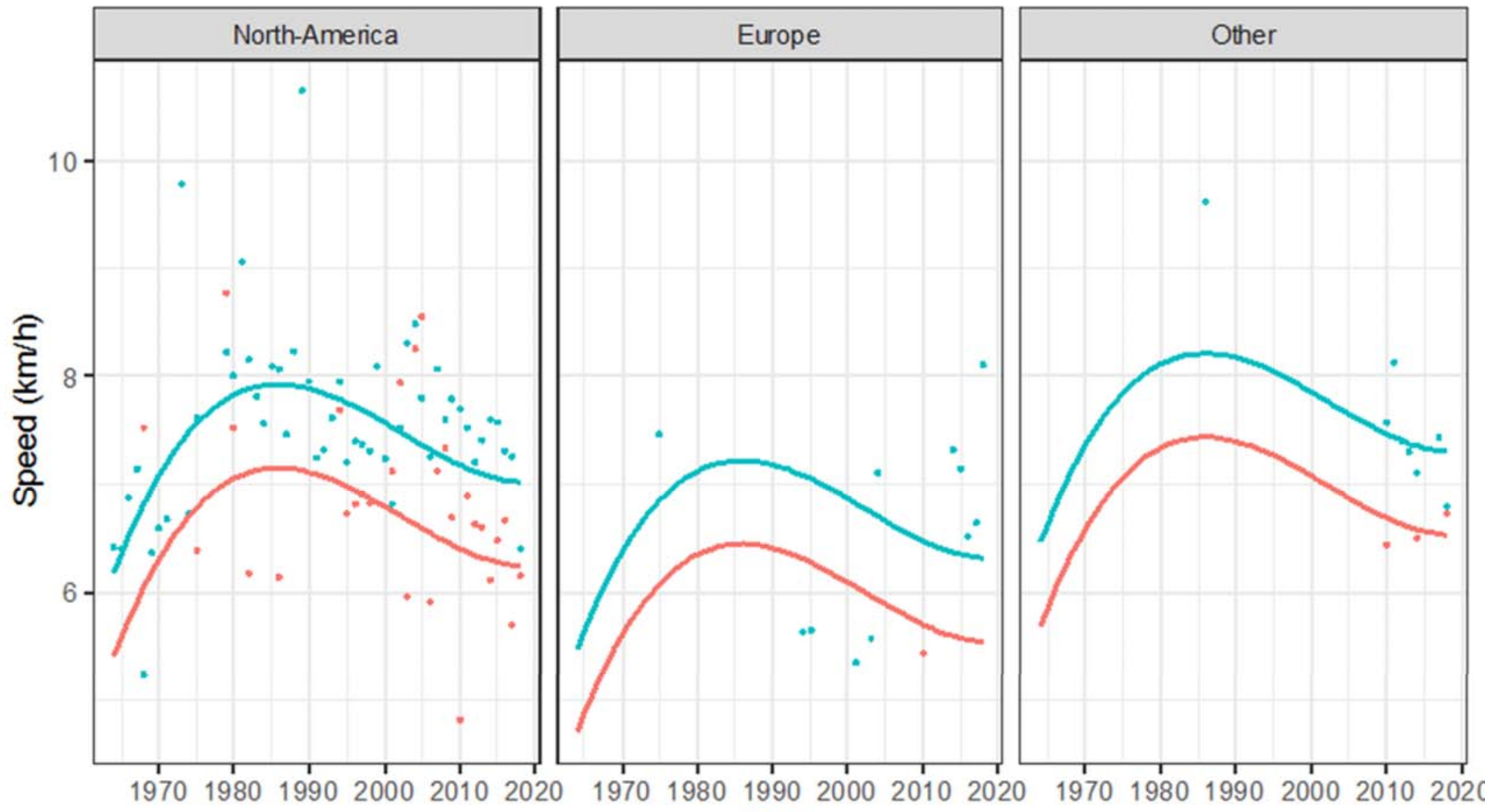

Sex

$-F$
$-M$

FigureS5 
100 km

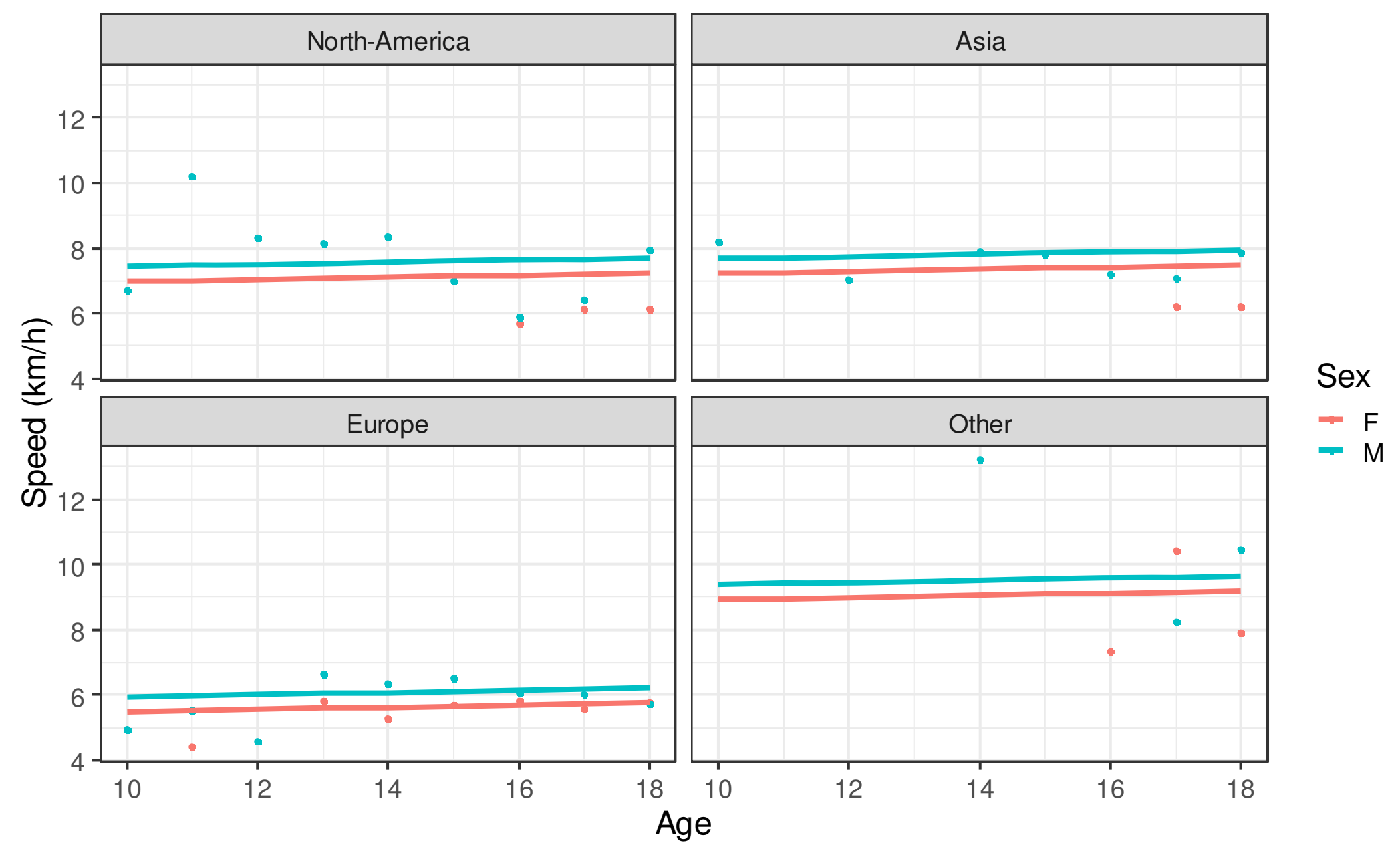

565

Figure S6 


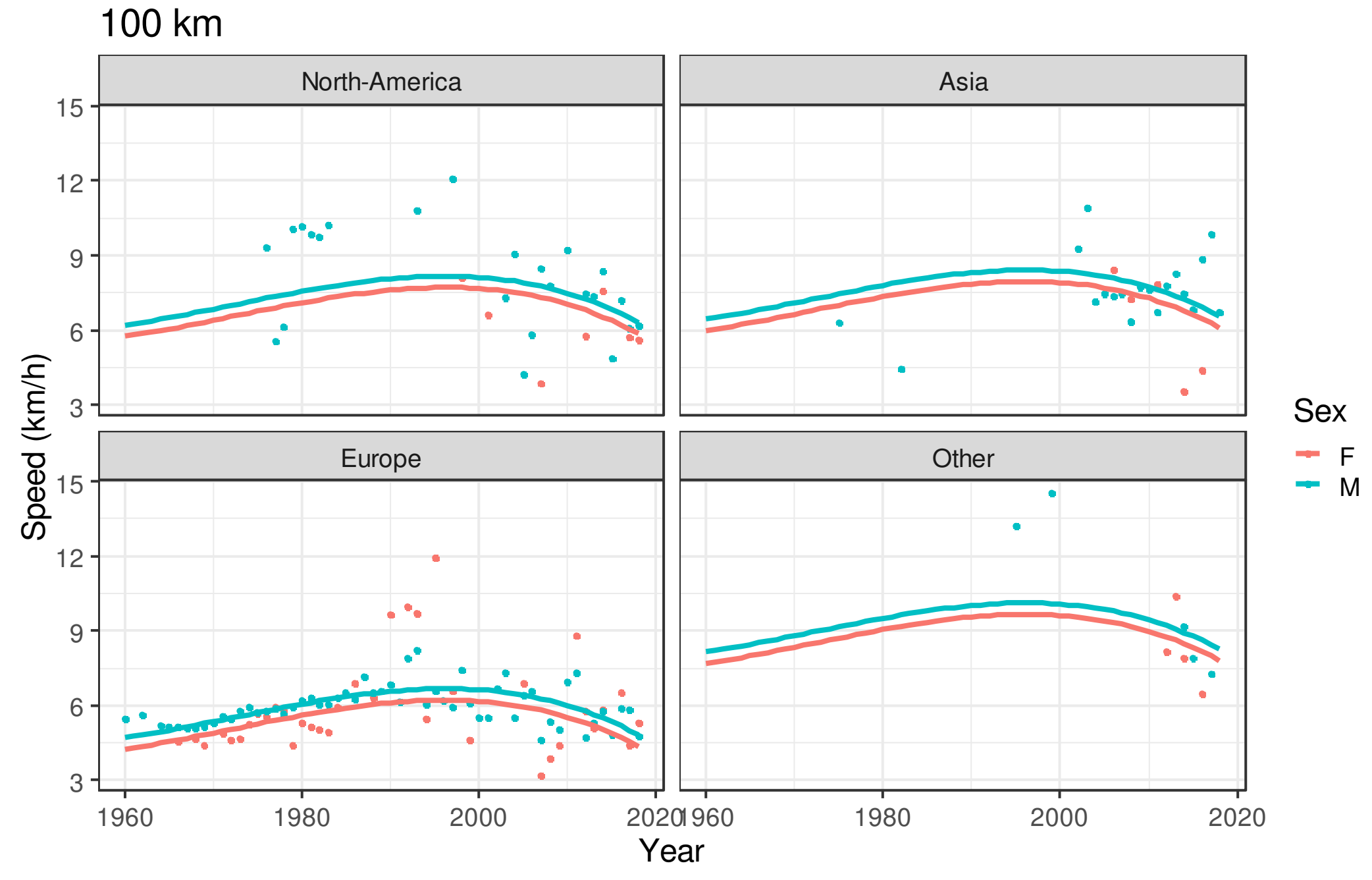

567

Figure S7 